\title{
Immunosuppressive therapy after human lung transplantation
}

\author{
C. Knoop*, A. Haverich", S. Fischer ${ }^{\#}$
}

Immunosuppressive therapy after human lung transplantation. C. Knoop, A. Haverich, S. Fischer. (C) ERS Journals Ltd 2004.

ABSTRACT: In 2002, equal numbers of lung transplantation (LTx) were performed with or without induction therapy with antilymphocyte antibodies, monoclonal antiCD3 antibody or anti-interleukin-2-receptor monoclonal antibodies. It remains to be established if induction therapy after LTx is beneficial or deleterious for long-term graft and patient survival.

The vast majority of lung transplant recipients receive a triple-drug maintenance regimen including a calcineurin inhibitor, a cell-cycle inhibitor and steroids. Equal proportions receive cyclosporin A (CsA) and tacrolimus (Tac). There is also a trend to prescribe mycophenolate mofetil (MMF) instead of azathioprine (Aza). Steroid withdrawal is uncommon even 5 yrs after transplantation.

The superiority of Tac over CsA as a maintenance agent has not been established to date, and the administration of MMF instead of Aza in combination with CsA and steroids did not improve graft or patient survival in a recent international, prospective, randomised, controlled trial.

Shift from cyclosporin A to tacrolimus has emerged as the first treatment step of refractory acute rejection followed by high-dose steroids or antilymphocyte agents, total lymphoid irradiation or photopheresis. The treatment of chronic rejection remains deceptive and includes varied strategies such as modification of the maintenance regimen, addition of inhaled immunosuppressants and/or total lymphoid irradiation and photopheresis.

Eur Respir J 2004; 23: 159-171.
*Dept of Chest Medicine, Erasme Hospital, Brussels, Belgium. ${ }^{\#}$ Dept of Thoracic and Cardiovascular Surgery, Hanover Medical School, Hanover, Germany.

Correspondence: C. Knoop

Dept of Chest Medicine

Erasme Hospital

808 Route de Lennik

1070 Brussels

Belgium

E-mail: cknoop@ulb.ac.be

Keywords: Acute rejection chronic rejection

immunosuppressant mechanism of action immunosuppressant toxic side-effects immunosuppression

Received: April 82003

Accepted: April 92003
During the last two decades lung transplantation (LTx) has become a life-saving intervention for patients presenting with end-stage respiratory disease. A successful lung transplant may result in complete restoration of lung function and normal quality of life in these very ill patients. Unfortunately, medium- and long-term results are less spectacular. Indeed, lung transplant recipients may not consider themselves cured as 5 -yr actuarial survival only approximates $50 \%$ [1]. The two main causes of death after LTx are bronchiolitis obliterans (BO), which is widely believed to be the expression of chronic rejection of the allograft bronchi/bronchioles, and infections [1]. Both complications are a sign of inadequate immunosuppression and, clearly, optimisation of the immunosuppressive strategy is of prime importance if medium- and long-term results are to be improved.

The discovery of cyclosporin A (CsA) has been a corner stone for the success of clinical LTx. LTx performed before the CsA era invariably failed, notably because the immune suppression provided by high-dose steroids in combination with azathioprine (Aza) resulted in prominent anastomotic complications and was insufficient to control acute rejection. As a result of this unfortunate experience and in line with immunosuppressive strategies then applied in renal and heart transplant recipients, the vast majority of patients, who underwent LTx from the early 1980s onwards, received a triple-drug maintenance regimen including CsA, Aza and steroids. Over time, the conservative approach of a triple-drug maintenance regimen has been maintained. In 2002, data from the Registry of the International Society for Heart and Lung Transplantation (ISHLT) indicated that $>95 \%$ of patients receive a calcineurin inhibitor, $80 \%$ receive a cellcycle inhibitor and $>95 \%$ receive steroids even 5 yrs after transplantation [2].

This chapter reviews present knowledge on immunosuppressive strategies after LTx, but also highlights unanswered questions that will have to be resolved by multicentre, prospective, randomised, controlled trials.

\section{Acute rejection after lung transplantation}

\section{The incidence of acute rejection}

The incidence of acute rejection episodes is increased after LTx compared with other types of organ transplantation. Data from a recent international trial including 315 patients

Previous articles in this series: No. 1: Glanville AR, Estenne M. Indications, patient selection and timing of referral for lung transplantation. Eur Respir J 2003; 22: 845-852. No. 2: Boehler A, Estenne M. Post-transplant bronchiolitis obliterans. Eur Respir J 2003; 22: $1007-1018$. 
(receiving a triple-drug regimen including CsA, Aza or mycophenolate mofetil (MMF) and steroids) indicated that the incidence of acute rejection is $54 \%$ at $1 \mathrm{yr}$ [3]. In comparison, the incidence of acute rejection at $1 \mathrm{yr}$ is $\leqslant 40 \%$, and can be as low as $17 \%$ in renal transplant patients [4].

There are multiple explications for the increased incidence of acute rejection after LTx. First, no prospective human leukocyte antigen (HLA) matching is or can be performed. Second, the lung graft, in contrast to all other transplanted organs, is in permanent contact with the external environment and is thus exposed to various inhaled agents, such as fumes, toxins and infectious agents, which may potentially cause local inflammation and trigger acute rejection. Finally, the lung graft contains a huge amount of donor antigen-presenting cells constantly processing and presenting HLA alloantigens to recipient lymphocytes that initiate a process of immune recognition.

\section{The diagnosis of acute rejection}

Acute rejection can be associated with fever, cough, dyspnoea and new adventitious lung sounds. These clinical signs are, however, nonspecific and do not distinguish between rejection and other causes of graft dysfunction. In addition, acute rejection may be clinically silent. Radiological abnormalities are only observed during the first few weeks. Thereafter, chest radiograph or high-resolution computed tomography are mainly unhelpful for the diagnosis of rejection.

Noninvasive diagnosis of acute rejection. Acute cellular rejection and infection typically produce an obstructive ventilatory defect [5-7]. The sensitivity of forced expiratory volume in one second (FEV1) measured at hospital for the detection of these complications ranges from $60-75 \%$ in recipients of heart and bilateral LTx [5-7], and from $48-72 \%$ in recipients of single LTx [8] when bronchoalveolar lavage (BAL) and transbronchial biopsies (TBB) are used as gold standard. On this basis, it has been recommended that lung transplant recipients perform daily measurements of FEV1 at home with a portable spirometer [9]. However, in a recent study, using daily monitoring of FEV1 and mid-expiratory flow at home with transmission of data to the hospital via the internet, the sensitivity of home spirometry for the detection of acute graft dysfunction was only $63 \%$ [10]. Thus, lung function is neither very sensitive nor specific for the diagnosis of acute rejection.

Two cross-sectional studies have investigated exhaled nitric oxide (eNO) as a tool for the detection of acute rejection. One study found that eNO increased during acute vascular rejection [11], while the other found an elevation during lymphocytic bronchiolitis but not during acute vascular rejection [12]. A recent study reported elevated levels of exhaled carbonyl sulphide in association with acute rejection, but data showed a large overlap with values obtained in stable patients [13].

Preliminary studies suggest that unlike BAL cellularity, BAL cytokine expression may show characteristic changes during acute rejection, but further studies are needed to confirm these results [14].

In conclusion, there is at present no sensitive and specific noninvasive tool available for the diagnosis of acute rejection, such that histology remains the gold standard.

Surveillance transbronchial biopsies: pros and cons. Owing to the impact of acute rejection on the development of chronic rejection and, thus, survival (see below), $66 \%$ of centres, which report data to the ISHLT registry, perform surveillance TBB at fixed intervals during the first postoperative year, in addition to TBB in the setting of new symptoms or signs [15]. The role of regularly scheduled TBB in completely asymptomatic lung transplant recipients, however, remains controversial.

Protagonists argue that clinical examination, chest radiography, spirometry and measures of gas exchange are nonsensitive and nonspecific for the diagnosis of acute rejection (see above). Previous studies have shown that surveillance TBB may show acute rejection histology in $22-73 \%$ of clinically and physiologically stable patients [16, 17]. Most importantly, the timely treatment of these silent episodes may eventually prove useful to uncouple the association between acute and chronic rejection [18].

Opponents retort that regularly scheduled TBB will only identify lower grades of acute rejection because grades 3 or 4 will not go without symptoms or signs. The impact of lower grade rejection on the development of chronic rejection, however, is not clear and the appropriate treatment of lower grade rejection remains controversial. Indeed, not all centres will give antirejection treatment for grades 1 or 2 acute rejection. Surveillance TBB will add risks and costs to the follow-up of lung transplant patients.

To date, there has been no prospective study to investigate the impact of surveillance TBB on the incidence of bronchiolitis obliterans syndrome (BOS) or survival. Some centres have even presented data supporting the fact that clinical outcome is satisfactory without surveillance TBB [19].

The questions of whether surveillance TBB should be performed and what is the impact of surveillance TBB on overall survival are clearly unsettled for the time being.

\section{The relationship between acute and chronic rejection}

Acute rejection, with a few exceptional cases, does not by itself cause death. However, it is a major determinant of longterm outcome as it (especially severe, recurrent and/or late acute rejection) has been identified as being the most significant risk factor for subsequent development of BOS/ BO [20]. That said, the exact relationship between acute rejection and BOS remains unclear at present. Some patients with acute rejection develop progressive BOS without an intervening time interval. In other patients, a long time period intervenes between the occurrence and successful treatment of acute rejection and the development of BOS. Finally, other patients still develop BOS without any diagnosed episode of acute rejection [21-23]. In any case, successful prevention of acute rejection must be the main target of immunosuppression after LTx.

\section{Prevention of acute rejection after lung transplantation}

\section{Induction therapy}

Rationale for induction therapy. The efficacy of biological agents (table 1) inducing profound T-lymphocyte depletion, such as antithymocyte globulins (ATG) or monoclonal antiCD3 antibody (OKT3), has led to their prophylactic use during the early postoperative period, a strategy called induction therapy. The rationale of induction therapy is to use the strongest immunosuppressive drugs at the time when the risk of rejection is highest, that is, in the first few weeks following transplantation [24]. Prospective, randomised studies in renal transplant recipients [25] and data provided by renal transplant registries [26] indicate that ATG or OKT3 induction therapy considerably reduces the incidence of acute rejection, and also increases long-term kidney graft survival by $\sim 5 \%$ compared 
Table 1.-Immunosuppressive drugs, their mechanisms of action and side-effects

\begin{tabular}{|c|c|c|}
\hline Agent & Mechanism of action & Side-effects \\
\hline ATG & $\begin{array}{l}\text { Fixes numerous antigens on lymphoid cells; depletion of } \\
\text { circulating lymphocytes }\end{array}$ & $\begin{array}{l}\text { Cytokine release syndrome } \\
\text { Leukopaenia, thrombopaenia }\end{array}$ \\
\hline OKT3 & $\begin{array}{l}\text { Fixes CD3 present on T-lymphocytes; depletion of } \\
\text { circulating lymphocytes }\end{array}$ & $\begin{array}{l}\text { Cytokine release syndrome } \\
\text { Pro-coagulation effect } \\
\text { Possible sensitisation with loss } \\
\text { of efficacy }\end{array}$ \\
\hline Daclizumab & $\begin{array}{l}\text { Binds the } \alpha \text {-chain of IL- } 2 \text { receptor; blocks the proliferation } \\
\text { induced by IL- } 2\end{array}$ & Unreported \\
\hline Basiliximab & $\begin{array}{l}\text { Binds the } \alpha \text {-chain of IL- } 2 \text { receptor; blocks the proliferation } \\
\text { induced by IL- } 2\end{array}$ & Unreported \\
\hline Cyclosporin A & $\begin{array}{l}\text { Binds cyclophylin; inhibits calcineurin; inhibits cytokine } \\
\text { gene transcription }\end{array}$ & $\begin{array}{l}\text { Nephrotoxicity } \\
\text { Hypertension } \\
\text { Hypercholesterolaemia } \\
\text { Hypertrichosis } \\
\text { Gingival hypertrophy }\end{array}$ \\
\hline Tacrolimus & $\begin{array}{l}\text { Binds FKBP-12; inhibits calcineurin; inhibits cytokine gene } \\
\text { transcription }\end{array}$ & $\begin{array}{l}\text { Nephrotoxicity } \\
\text { Hypertension } \\
\text { Neurotoxicity } \\
\text { Diabetes mellitus } \\
\text { Alopecia }\end{array}$ \\
\hline Azathioprine & Inhibits purine biosynthesis and lymphocyte proliferation & Leukopaenia \\
\hline Mycophenolate mofetil & Inhibits purine biosynthesis and lymphocyte proliferation & $\begin{array}{l}\text { Diarrhoea } \\
\text { Leukopaenia }\end{array}$ \\
\hline Sirolimus/everolimus & $\begin{array}{l}\text { Binds FKBP-12; inhibits the proliferative response to } \\
\text { cytokines and growth factors }\end{array}$ & $\begin{array}{l}\text { Hyperlipaemia } \\
\text { Thrombocytopaenia } \\
\text { Arthralgia }\end{array}$ \\
\hline
\end{tabular}

ATG: antithymocyte globulin; OKT3: monoclonal anti-CD3 antibody; IL: interleukin; FKBP: FK (tacrolimus)-binding protein.

with conventional therapy (CsA (Sandimmune $\mathbb{R}$; Novartis Pharma AG, Basel, Switzerland), Aza and steroids). In patient groups that present a high risk of rejection, such as children, Black patients or patients with high levels of anti-HLA antibodies, the beneficial effect of these agents is even greater, allowing up to a $20 \%$ improvement in kidney graft survival after 3-5 yrs.

Data from the ISHLT registry indicate that $\sim 45 \%$ of lung transplant patients receive some type of induction therapy ( $\sim 20 \%$ polyclonal antilymphocyte preparations, $\sim 20 \%$ antiinterleukin (IL)-2-receptor antibodies, 4\% OKT3) [2]. It has to be stressed that the type of product used, its dosage and the duration of administration vary widely. The rationale for induction therapy after LTx is triple. First, lung transplant recipients per se can be considered to be at a high risk of rejection (see above). Second, induction therapy leaves a comfortable time-frame to achieve target levels of calcineurin inhibitors without exposing the patient to the risk of early acute rejection. Third, induction therapy allows renal function to recover from operative stresses, such as hypovolaemia or negative effects of cardiopulmonary bypass without being exposed to the toxic effects of calcineurin inhibitors [27]. The use of induction therapy after LTx, however, remains controversial as its benefits have not been clearly established and there is a potential for increased post-transplant infections, especially cytomegalovirus (CMV) infection, and post-transplant malignancies.

Polyclonal antilymphocyte antibodies. ATG preparations are obtained by injecting rabbits or horses with human thymic cells or lymphocytes and the subsequent isolation and purification of antibodies against human cells. They contain antibodies targeting numerous membrane antigens, some of which are solely present on T-cells, such as CD3, CD4 or CD8, whereas others, like the adhesion molecules CD11b and CD18, are also found on other circulating cells [28]. Initially, the treatment induces a rapid and profound lymphopaenia through several Fc-receptor-dependent mechanisms, such as complementdependent cytolysis, cell-mediated antibody-dependent cytolysis, as well as opsonisation and phagocytosis by macrophages. In addition, ATG preparations also modulate T-cell function through nondepletive mechanisms.

There has been only one single-centre, prospective, randomised study comparing ATG induction therapy versus conventional therapy alone (CsA, Aza, steroids) in 44 single- or bilateral-lung transplant patients. Induction therapy consisted of rabbit ATG (local preparation) $1.5 \mathrm{mg} \cdot \mathrm{kg}^{-1} \cdot \mathrm{day}^{-1}$ for 3 days. The incidence of biopsy-proven rejection (at least grade A2) was $23 \%$ at $1 \mathrm{yr}$ in the ATG group versus $55 \%$ in the control group. In addition, there was a nonsignificant reduction in the incidence of BOS in the induction group at $3 \mathrm{yrs}$. The incidences of post-transplant infections and malignancies were not different between the two groups and actuarial survival was identical at 1 and 2 yrs follow-up [29]. These results are consistent with a previous retrospective study indicating that ATG induction may reduce the incidence of acute rejection without resulting in a concomitant improvement in survival [30].

Monitoring of peripheral CD3+ T-lymphocytes reduces the cost of ATG induction treatment, but also helps prevent overimmunosuppression and haematological complications in renal transplant recipients [31, 32]. KRASINSKAS et al. [33] applied this concept to 36 lung transplant patients, who received ATG either for induction therapy or for treatment of acute or chronic rejection, and whose absolute $\mathrm{CD} 3+\mathrm{T}$ cell counts were maintained between $50-100$ cells $\mu \mathrm{L}^{-1}$. The dose of ATG could be reduced from $10-15 \mathrm{mg} \cdot \mathrm{kg}^{-1} \cdot \mathrm{day}^{-\mathrm{i}}$ to $1-5 \mathrm{mg} \cdot \mathrm{kg}^{-1} \cdot \mathrm{day}^{-1}$ without altering the efficacy of the treatment.

Monoclonal anti-CD3 antibody. OKT3 is a monoclonal mouse antibody directed against the CD3 complex, a series of proteins 
associated with the T-lymphocyte antigen receptor (TCR). OKT3 binds to the CD3 complex and induces depletion of circulating T-lymphocytes, as well as modulation of the TCRCD3 complex. The use of OKT3 for induction therapy after LTx has been very limited because the first dose of this agent frequently causes a cytokine release syndrome, which may induce cardiopulmonary instability [34, 35], and because of concerns regarding a possible increased risk of infections and malignancies.

WAIN et al. [23] treated 52 patients with a standard OKT3 dose of $5 \mathrm{mg} \cdot \mathrm{day}^{-1}$ for 10 days combined with oral CsA and Aza; maintenance steroids were begun on postoperative day 8. Acute rejection was never seen during OKT3 administration, and 14 of 52 patients did not present any acute rejection episode during a median follow-up of 31 months. In the remaining patients, acute rejection episodes responded readily to steroids or ATG. Freedom from BOS was $69 \%$ at 36 months. These authors concluded that OKT3 is safe and effective for induction immunosuppressive therapy in lung transplant recipients, and that its use may limit the incidence of acute and chronic rejection. However, this conclusion is weakened by the absence of a control group [23].

Anti-interleukin-2-receptor monoclonal antibodies. IL-2 serves as a cell-cycle progression signal for T-lymphocytes stimulating their proliferation and differentiation. IL-2 binds to a highaffinity receptor located on T-cells, which is formed by three transmembrane proteins: CD25, CD122 and CD132. One of the earliest events after T-cell activation is upregulation of expression of CD25, after which the two other proteins rapidly associate with CD25, rendering T-cells exquisitely responsive to IL-2. Monoclonal antibodies (mAbs) directed against the IL-2 receptor will selectively block activated T-cells, whereas polyclonal ATG and OKT3 will nonselectively block and deplete both quiescent and activated T-cells. Rodent anti-IL-2receptor $m A b s$ have been associated with a lack of efficacy due to rapid development of neutralising antibodies and with a severe side-effect profile. The development of chimeric or humanised anti-IL-2-receptor mAbs (keeping from the murine parent antibody only the variable regions or the antigenbinding sequences, respectively) has circumvented these problems and has permitted their introduction into the clinic.

In renal transplant patients, the administration of antiIL-2-receptor $m A$ bs during the first weeks after transplantation has resulted in a decrease of acute rejection episodes when compared with conventional immunosuppression without any increase in toxicity and/or in bacterial or viral infections [36-38]. In heart transplant patients, the administration of five doses of daclizumab reduced the incidence of acute rejection when compared with a standard regimen including CsA, MMF and steroids, however, the beneficial effect was mainly observed during the first 3 months after transplantation [39].

In lung transplant patients, BROCK et al. [40] conducted a 4-yr prospective study enrolling 87 lung transplant recipients split into three groups: group 1 received OKT3, group 2 received ATG and group 3 received daclizumab. There was no difference in freedom from acute rejection or BOS at 2 yrs, and no difference in patient survival. Patients receiving OKT3 $(n=30)$ had significantly more infections, mainly bacterial; this difference became significant only 2 months after transplantation [40]. GARRITY et al. [41] retrospectively compared the incidence of acute rejection in 27 patients who received daclizumab induction therapy with the incidence of acute rejection in a historical control group of 34 patients receiving tacrolimus (Tac), Aza and steroids. At 6 months after transplantation, $82 \%$ of patients were free of rejection compared with $52 \%$ in the control group. There was no increased incidence of infection [41].

Summary. Thus, there is some evidence that induction therapy after LTx may reduce and delay acute rejection episodes and also reduce the incidence of chronic rejection. Unfortunately, there are no large, prospective, randomised, placebocontrolled trials to establish the benefits of induction therapy compared with conventional immunosuppression convincingly and to compare different agents used for induction. From the available data (table 2), induction with ATG seems a good choice, induction with OKT3 is probably less safe, and more data on induction with anti-IL-2 receptor mAbs should be obtained. It also has to be stressed that, currently, there are no data to suggest that induction therapy after LTx should be abandoned.

\section{Maintenance therapy}

Maintenance immunosuppression aims at preventing acute rejection. Most lung transplant patients continue to receive triple-drug regimens in the long term [2]. These regimens are thought to be more effective than dual- or single-drug regimens, and the combination of three different drugs is expected to minimise side-effects of individual drugs. With the discovery of new drugs, combinations are now varied, but still always contain an association of a calcineurin inhibitor, a cellcycle inhibitor and steroids.

Calcineurin inhibitors. Cyclosporin A. In 2002, the ISHLT registry indicated that $40-50 \%$ of all lung transplant recipients receive $\mathrm{CsA}$ as part of the maintenance immunosuppressive regimen at 1 and 5 yrs after transplantation [2].

The immunosuppressive properties of CsA were discovered in 1976 [45] and this revolutionised the practice of solid organ transplantation [46]. CsA is a cyclic peptide produced by the fungus Tolypocladium inflatum. CsA acquires its active form when penetrating into the cell and forming complexes with cytoplasmic proteins, called cyclophilins. The CsA-cyclophilin complexes bind to calcineurin in the cytoplasma. Calcineurin normally acts as a phosphatase that dephosphorylates nuclear regulatory proteins, such as the nuclear factor of activated Tcells, facilitating their passage through the nuclear membrane, where they act as transcription factors for the activation of the promoter regions of various cytokines. The CsA-cyclophilin complexes inactivate the enzymatic activity of calcineurin and, thus, ultimately inhibit the transcription of cytokines, namely IL-2, $-3,-4$ and -5 , interferon- $\gamma$, tumour necrosis factor- $\alpha$ and granulocyte/macrophage colony-stimulating factor. The limited amount of calcineurin in immune cells compared with nonimmune cells, and the fact that calcineurin is critical to $\mathrm{T}$-cell activation accounts for the exquisite sensitivity of T-lymphocytes to CsA [47]. In addition, CsA enhances, presumably by a distinct mechanism, the expression of transforming growth factor- $\beta$, which on one hand inhibits IL-2-stimulated T-cell proliferation and generation of cytotoxic T-lymphocytes, and on the other hand, exerts a profibrogenous effect.

CsA is a highly lipophilic molecule with wide interpatient and intrapatient variation in absorption and low oral bioavailability. A microemulsion formulation of CsA (Neoral®); Novartis Pharma AG), designed to increase the dispersion and solubility of CsA in the small bowel was introduced in 1996. This formulation reduces the effects of food and the presence of bile on absorption. It presents improved pharmacokinetic parameters compared with the original olive oil-based formulation (Sandimmune $\mathbb{R}$ ) and assures: 1) a 


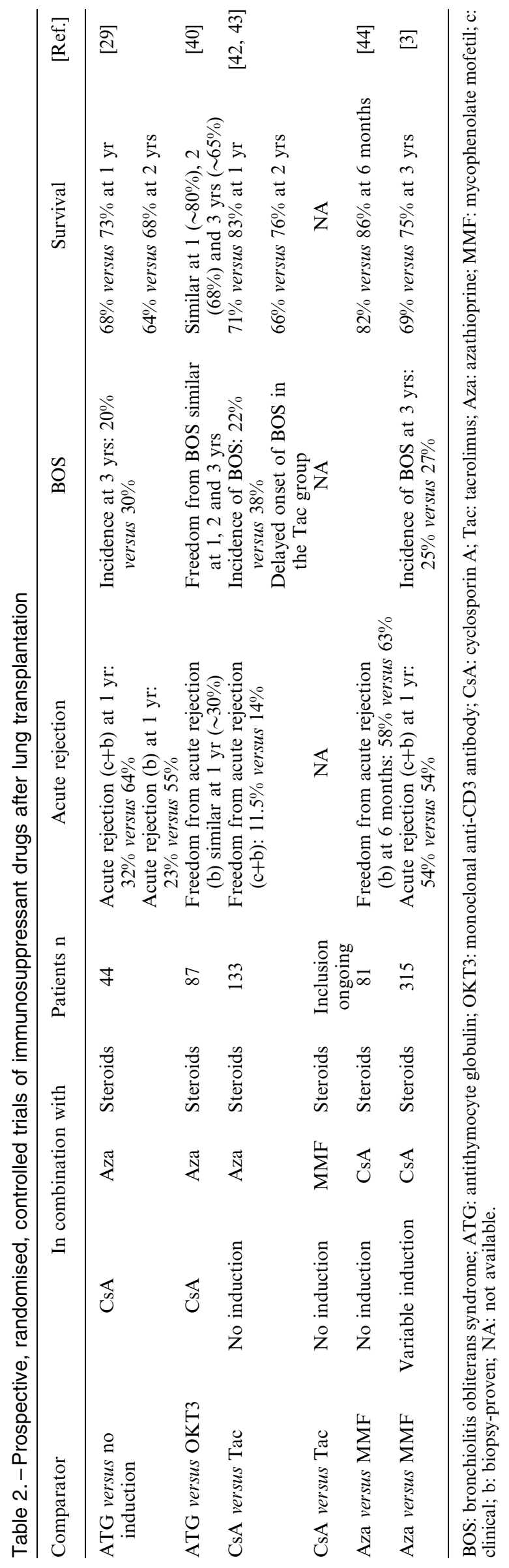

shorter time to maximum blood concentration; 2) a higher maximum blood concentration; 3) a higher area under the concentration/time curve (AUC); and 4) a lower intrasubject variability for time to maximum concentration, maximum concentration, minimum blood concentration $(\mathrm{Cmin}$ or $\mathrm{C} 0$ ), AUC, and percentage peak-trough fluctuation [48].

For nearly two decades, CsA dosages have been adapted according to the morning trough level ( $\mathrm{Cmin}$ or $\mathrm{C} 0$ ). Multiple studies have demonstrated, though, that $\mathrm{C} 0$ is poorly correlated with systemic exposure to CsA, as assessed by a full pharmacokinetic profile over $12 \mathrm{~h}(\mathrm{AUC} 0-12)$ or by a pharmacokinetic profile during the first $4 \mathrm{~h}$ after administration $(\mathrm{AUC0}-4)$ in recipients of kidney, liver and heart transplantation [49]. More importantly, low systemic exposure to CsA indicated by a low $\mathrm{AUC}_{-} 4$ has been recognised as a significant risk factor for acute rejection, whereas high systemic exposure has been associated with increased nephrotoxicity in renal transplant patients [50, 51]. The time-frame within which AUC0-4 target values are achieved also seems to be of prime importance. In a prospective trial, including 55 renal transplant patients, only $3 \%$ of patients who achieved a target AUC $0-4$ of $4,500-5,500 \mathrm{ng} \cdot \mathrm{h}^{-1} \cdot \mathrm{mL}^{-1}$ within 3 days of transplantation presented acute rejection during the first 3 months compared with $45 \%$ of patients who did not achieve this target [52]. Finally, high variability in systemic exposure has been associated with an increased risk of chronic rejection in renal transplant patients [53]. In the light of these observation, methods to assess systemic exposure to CsA in individual patients have been designed in order to optimise clinical outcomes.

The AUC0-12 gives a complete picture of CsA absorption, elimination and patient exposure. It is, however, impractical to obtain in the clinical setting because of inconvenience and cost. It also has to be stressed that the greatest variability in CsA absorption occurs in the first $4 \mathrm{~h}$ after administration. It has also been shown that the immunosuppressive effect of CsA is maximal and most consistent around the peak absorption time, which is within $2 \mathrm{~h}$ of the dose [54]. Thus, the determination of $\mathrm{AUC} 0-4$ will probably reflect most of the differences in exposure between, and within, individuals. However, the routine determination of $\mathrm{AUCO}_{-4}$ is also difficult to apply clinically. Fortunately, it has been established that sparse-sampling strategies may be very good predictors of AUC0-4 [55]. Measuring CsA levels $2 \mathrm{~h}$ after the morning dose $(\mathrm{C} 2)$ is an especially excellent predictor of AUC0-4 in most adult renal, heart and liver transplant recipients [56]. Thus, it is expected that $\mathrm{C} 2$ monitoring will reduce the incidence of acute and chronic rejection in solid organ transplant patients on CsA. In addition, $\mathrm{C} 2$ monitoring may improve renal function and reduce the incidence of hypertension after transplantation by identifying patients who are receiving excessive doses of CsA. For all these reasons, the use of $\mathrm{C} 2$ monitoring is now strongly encouraged and target values for $\mathrm{C} 2$ according to the time interval from transplantation have been established for adult renal and liver transplant recipients [49].

Very little data on CsA monitoring after LTx are available. In a randomised trial, TRULL et al. [57] found that the AUC0-6 was better predicted by $\mathrm{C} 2$ than by $\mathrm{C} 0$. DUMONT et al. [58] studied 14 lung transplant recipients and showed that the AUC0-12 was best predicted by a sparse-sampling strategy including $\mathrm{C} 0$ and $\mathrm{C} 3$ [58]. These results, however, may not apply to all lung transplant recipients, in particular those with cystic fibrosis (CF) who may have a different pharmacokinetic profile of $\mathrm{CsA}$, due to the presence of fat malabsorption associated with CF-related exocrine pancreatic insufficiency [59, 60]. Preliminary data from a few small, single-centre studies indicate that $\mathrm{C} 2$ is a valuable tool for predicting $\mathrm{AUC} 0-12$ or $\mathrm{AUC} 0-4$ in $\mathrm{CF}$ and non-CF patients 
$[61,62]$. These data have to be expanded to propose recommendations for optimal therapeutic drug monitoring of CsA in lung transplant recipients, and target values for AUC0-4 and $\mathrm{C}_{2}$ will have to be established.

Tacrolimus. Over the last few years there has been a clear trend to use Tac instead of CsA as part of the maintenance immunosuppressive regimen. In $1999, \sim 70 \%$ of lung transplant patients received $\mathrm{CsA}$ and $26 \%$ received Tac at $1 \mathrm{yr}$ after transplantation; corresponding values at 4 yrs after surgery were $\sim 60$ and $36 \%$, respectively [63]. In 2002, equal proportions of lung transplant recipients were receiving CsA or Tac, 1 and 5 yrs after transplantation [2].

Tac was discovered in 1984 and is a hydrophobic macrocyclic lactone derived from the actinomycete Streptomyces tsukubaensis. Tac suppresses the immune system by similar mechanisms to CsA. It binds in the cytoplasm with FK (Tac)-binding proteins (FKBPs), and the Tac-FKBP complexes associate with calcineurin. Tac is $50-100$ times more potent than CsA in vitro due to differences in partition coefficients and increased binding affinity of Tac to FKBPs [47].

Tac, like CsA, has a narrow therapeutic window and significant systemic side-effects. Absorption after oral administration is poor, with maximum blood concentration occurring $4 \mathrm{~h}$ after intake. In contrast to CsA, the absorption of Tac is hindered by food but is completely independent of the presence of bile. The oral bioavailability and maximum concentration of Tac is highly variable between and within patients. The low and variable bioavailability of Tac is caused by its transformation in the gut wall by cytochrome P450 enzymes, and by a countertransport of the parent drug and metabolites by the multidrug resistance transporter p-glycoprotein.

Tac dosage is mainly adapted to $\mathrm{C} 0$ levels. The relationship between $\mathrm{C} 0$ and AUC varies widely in clinical trials with correlations ranging 0.11-0.92 [64]. Postdose-monitoring strategies will probably be developed in the near future. Some data on postdose-monitoring strategies of Tac after LTx are already available $[65,66]$; these have to be expanded.

Cyclosporin A versus tacrolimus. Studies comparing CsA versus Tac in renal transplant patients have established different facts. First, CsA-Sandimmune $\mathbb{R}$ versus Tac in combination with OKT3 induction therapy, Aza and steroids resulted in a similar patient and graft survival at 5-yrs

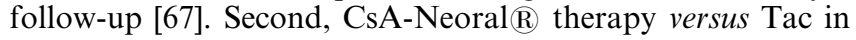
combination with Aza and steroids resulted in a reduced incidence of biopsy-confirmed acute rejection in patients receiving Tac with no differences in patient or graft survival in the long run in a single centre [68], as well as at 6 months in a European multicentre study [69]. A metaanalysis of eight randomised trials comparing CsA with Tac confirmed that immunosuppression with Tac resulted in a significant decrease in episodes of acute rejection compared with CsA-based treatment. This analysis, however, also failed to show any positive effect of Tac on patient or graft survival at $1 \mathrm{yr}$ after transplantation [70].

In heart transplant recipients, two prospective, randomised, open-label, multicentre, and two prospective, randomised, single-centre studies comparing CsA with Tac failed to show a significant reduction of acute rejection and/or a benefit in survival with Tac [71-74].

There are only three studies evaluating the efficacy of CsA versus Tac after LTx. KEENAN and co-workers [42, 43] randomised 133 recipients to receive either CsA or Tac combined with Aza and steroids. Less acute rejection episodes and significantly less BOS (38\% versus $22 \%$ ) were observed in the Tac group. There was also a nonsignificant trend to improved survival at 2 yrs [42] and a delayed development of BOS in the Tac group [43]. TREEDE et al. [75] evaluated CsA versus Tac in combination with $\mathrm{MMF}\left(2 \mathrm{~g} \cdot \mathrm{day}^{-1}\right)$ and steroids in a prospective, randomised, open, two-centre trial, including 50 lung transplant recipients. All patients also received induction therapy with rabbit antithymocyte globulin (RATG) for 3 days. Freedom from acute rejection tended to be higher in the Tac group at 6 and 12 months, but survival at 12 months was similar [75]. The same investigators had previously conducted a retrospective study including 78 consecutive patients receiving: 1) RATG induction, CsA, Aza and steroids (n=34); 2) Tac, Aza and steroids ( $=30)$; or 3 ) Tac, MMF and steroids $(n=12)$. The number of acute rejection episodes per patient was lower, and freedom from recurrent acute rejection was significantly higher in the Tac groups. However, after $3 \mathrm{yrs}$, there was no significant difference in the rate of development of chronic rejection in the first two groups. Survival was significantly better in the Tac, Aza and steroids' group compared with the CsA, Aza and steroids' group (93\% versus $71 \%$ at $1 \mathrm{yr}$; $71 \%$ versus $51 \%$ at $3 \mathrm{yrs}$ ). The Tac, MMF and steroids' group could not yet be evaluated for BOS and survival because of a limited followup. The significance of these interesting findings is, however, weakened by the small number of patients and the retrospective design of the study [76].

From these studies no firm conclusion can be drawn as to the respective merits of $\mathrm{CsA}$ and Tac for the prevention of acute and chronic rejection after LTx. An international, prospective, randomised trial comparing CsA versus Tac in combination with MMF (2-4 g.day ${ }^{-1}$ according to mycophenolic acid (MPA) trough levels) and steroids without induction therapy is currently under way. More than 200 patients have been included so far. The 1-yr interim analysis of this trial, due in autumn 2003, will hopefully provide some clues as to which calcineurin inhibitor is the most efficacious and/or less toxic in the setting of LTx. It should be remembered that $\mathrm{CsA}$ administration in this trial was guided by $\mathrm{C} 0$, a method that has been largely invalidated during the course of the trial (see above). Thus, if CsA turns out to be second choice compared with Tac, a follow-up trial comparing CsA monitored by sparse-sampling AUC strategies or single postdose levels versus Tac will probably be necessary.

Cell-cycle inhibitors. Azathioprine. Aza inhibits both deoxyribonucleic acid and ribonucleic acid synthesis, interferes with the precursors of purine synthesis and suppresses de novo purine synthesis. It has an effect on proliferation of $\mathrm{T}$ - and B-lymphocytes, but does not affect the production of cytokines. It also has an anti-inflammatory action, probably mainly due to its effect on proliferating cells.

Mycophenolate mofetil. The use of MMF instead of Aza has also increased since its commercialisation and testing in renal and heart transplantation. In 1999, 20\% of lung transplant patients received $\mathrm{MMF}$ at $1 \mathrm{yr}$ and $25 \%$ at 4 yrs after transplantation [63]. Corresponding values in 2002 are $\sim 40 \%$ at $1 \mathrm{yr}$ and $\sim 35 \%$ at 5 yrs [2].

MMF is a pro-drug, a morpholinoethyl ester of MPA, which is the active compound. MPA was initially derived from Penicillium sp. cultures in 1896. MPA is a noncompetitive reversible inhibitor of inosine monophosphate dehydrogenase, which is the rate-limiting enzyme in the de novo pathway for purine synthesis. Resting lymphocytes rely on the salvage pathway for purine biosynthesis; activated lymphocytes rely on both the de novo and the salvage pathway. MPA suppresses T-and B-cell proliferation more potently than that 
of other rapidly dividing cells, such as neutrophils and erythrocytes that can use the salvage purine synthesis pathway instead [47].

MMF is highly soluble at the lower $\mathrm{pH}$ of the upper gastrointestinal tract and is rapidly absorbed. The liver is the primary location for hydrolysis of MMF to MPA and an inactive metabolite. The inactive metabolite is excreted in the bile; some of it is reconverted to MPA by gut enzymes and undergoes enterohepatic recirculation. This recirculation causes secondary MPA peaks to appear in the plasma 6-12 $\mathrm{h}$ postdose.

MPA concentrations are lower in transplant recipients receiving $\mathrm{MMF}$ in combination with CsA than in patients receiving MMF with Tac. It is hypothesised that CsA attenuates the enterohepatic circulation of MPA and its glucuronide metabolite [77]. The standard dose of MMF in combination with CsA is thus $3 \mathrm{~g} \cdot \mathrm{day}^{-1}$, whereas in combination with Tac it is $2 \mathrm{~g} \cdot \mathrm{day}^{-1}$.

There are large interindividual and intraindividual variations in MPA pharmacokinetic parameters [64]. As with CsA, there is mounting evidence that systemic exposure to MPA, as measured by the AUC, is correlated to clinical events [78]. However, trough MPA levels seem poorly correlated to the 12-h AUC of MPA, so that therapeutic drug-monitoring strategies for MMF will also have to be refined in the near future [64]. Substantial intrasubject variability for AUC and maximum blood concentration has also been demonstrated in the pharmacokinetic substudy of the international trial comparing Aza with MMF after LTx (see below).

Azathioprine versus mycophenolate mofetil. The use of MMF has reduced the incidence of acute rejection in renal and heart transplant recipients. In renal transplant patients, a pooled efficacy analysis of three large, prospective, randomised, double-blind studies compared Aza with two different doses of MMF, 2 and $3 \mathrm{~g} \cdot \mathrm{day}^{-1}$. The incidence of acute rejection episodes at 1 yr was $41 \%$ with Aza, 20\% with MMF $2 \mathrm{~g} \cdot \mathrm{day}^{-1}$ and $17 \%$ with MMF $3 \mathrm{~g} \cdot \mathrm{day}^{-1}$. Survival was 88,90 and $89 \%$, respectively [4]. In heart transplant recipients, a prospective, randomised, doubleblind study, including 578 patients comparing Aza $\left(1.5-3 \mathrm{mg} \cdot \mathrm{kg}^{-1} \cdot \mathrm{day}^{-1}\right)$ to MMF $\left(3 \mathrm{~g} \cdot \mathrm{day}^{-1}\right)$ combined with CsA and steroids, showed a significant reduction in acute rejection episodes (74\% Aza versus 66\% MMF) and a significantly better survival (89\% Aza versus 94\% MMF) at $1 \mathrm{yr}$ in the MMF group [79].

The role of MMF in the setting of LTx has been investigated in several studies. PALMER et al. [44] conducted a prospective, randomised, multicentre study in 81 consecutive lung transplant patients. Patients received CsA, steroids, and either Aza $\left(2 \mathrm{mg} \cdot \mathrm{kg}^{-1} \cdot \mathrm{day}^{-1}\right)$ or $\operatorname{MMF}\left(2 \mathrm{~g} \cdot \mathrm{day}^{-1}\right)$. The incidence of biopsy-proven acute rejection ( $\geqslant$ grade A2) was $58 \%$ in the Aza group versus $63 \%$ in the MMF group at 6 months. Rates of CMV infection were not significantly different at 6 months and survival was identical. The authors concluded that acute rejection rates and overall survival at 6 months were similar in patients treated with Aza or MMF [44]. In contrast, three small, nonrandomised studies suggested a decreased incidence of biopsy-proven acute rejection episodes with $\mathrm{MMF}$ and/or a reduced incidence of BOS, and/or a delayed onset of BOS. O'HAIR et al. [80] evaluated MMF as the primary immunosuppressant in 13 lung transplant recipients and observed a decrease in the acute rejection rate during the first 3 months compared with historical controls treated with Aza. Ross et al. [81] conducted a two-centre, nonrandomised, concurrent cohort study including 22 patients receiving ATG induction, CsA, steroids and either Aza $\left(1-2 \mathrm{mg} \cdot \mathrm{kg}^{-1} \cdot \mathrm{day}^{-1}\right)$ or MMF $\left(2 \mathrm{~g} \cdot \mathrm{day}^{-1}\right)$. This study showed a decreased incidence of acute rejection in the MMF group and a nonsignificant, decreased prevalence of BOS at 12 months in the MMF group, with no significant differences in the incidence of infections [81]. ZUCKERMANN et al. [82] treated 38 consecutive patients with ATG induction therapy, CsA, steroids and MMF $\left(2 \mathrm{~g} \cdot \mathrm{day}^{-1}\right)$ and compared this group with a historical control group that had received Aza $\left(1.5-2 \mathrm{mg} \cdot \mathrm{kg}^{-1} \cdot \mathrm{day}^{-1}\right)$ instead of MMF. The data obtained at 6 months follow-up also indicated a significant reduction of acute rejection in the MMF group without any difference in the incidence of infections [82]. Thus, data from small studies using mainly historical controls suggest that MMF may be more efficient than Aza for the prevention of acute rejection in LTx, whereas the only prospective, randomised study of Aza versus MMF does not suggest any benefit.

Recently, an international trial was conducted comparing a combination of CsA, steroids and Aza $\left(2 \mathrm{mg} \cdot \mathrm{kg}^{-1} \cdot \mathrm{day}^{-1}\right)$ or MMF ( $3 \mathrm{~g} \cdot \mathrm{day}^{-1}$ for 3 months, then $\left.2 \mathrm{~g} \cdot \mathrm{day}^{-1}\right)$, in lung transplant recipients, in a prospective and randomised fashion. The administration of induction therapy was left to the discretion of the clinicians. The 3 -yr analysis of this trial including 315 patients indicates that the incidence of acute rejection, delay to acute rejection, and the incidence of BOS and infections were similar in the two groups. Survival at 3 yrs was $69 \%$ in the Aza group and $75 \%$ in the MMF group, which was not statistically significant [3].

Thus, at the present time, there are no firm data that indicate the superiority of MMF over Aza in the setting of LTx, and there seems to be no other reason than its more specific mode of action to make MMF the first-choice, cellcycle inhibitor.

Steroids. Most clinical lung transplant programmes rely on triple-agent immunosuppression including steroids. The use of steroids in the early postoperative phase has been controversial. Most physicians have adopted the use of a moderate dose of steroids; methylprednisolone $1-0.5 \mathrm{mg} \cdot \mathrm{kg}^{-1} \cdot \mathrm{day}^{-1}$ intravenously for several days before initiating an oral dose of prednisone $0.5 \mathrm{mg} \cdot \mathrm{kg}^{-1} \cdot \mathrm{day}^{-1}$. The withholding of steroids for the first few days seems to have neither beneficial nor adverse effects on bronchial healing. Steroid administration is gradually reduced to minimise the complications of long-term use $[27,83]$. There are, at the present time, no formal reports either on strategies for weaning steroids or on altogether steroid-free immunosuppressive regimens after LTx.

Summary. At the present time, triple-drug maintenance therapy is still the norm after LTx. The benefits that novel therapeutic drug-monitoring strategies for CsA have procured, in terms of prevention of acute rejection and toxicity after renal and liver transplantation, will hopefully be reproduced in the setting of LTx. In any case, it is expected that the administration of CsA using these tools will be fine-tuned in lung transplant patients in the near future.

To date, it is still unknown if primary Tac maintenance therapy may result in better prevention of acute and chronic rejection than $\mathrm{CsA}$, and whether Tac should preferably be associated to Aza or to MMF. It is clearly worthwhile to investigate if novel therapeutic drug-monitoring strategies, such as those developed for CsA, are also applicable to Tac.

MMF does not seem to procure benefits over Aza, at least when given at a dosage of $2 \mathrm{~g} \cdot \mathrm{day}^{-1}$ in combination with CsA and monitored according to $\mathrm{C} 0$.

Weaning of steroids surely cannot be advocated for each and every lung transplant patient in 2002. 


\section{Treatment of acute rejection}

\section{Uncomplicated acute rejection}

Acute rejection is treated by intravenous steroid pulses, specifically by three to five doses of $1 \mathrm{~g}$ or $500 \mathrm{mg}$ methylprednisolone per day, usually followed by an increase in the oral prednisone dose to 1.0 or $0.5 \mathrm{mg} \cdot \mathrm{kg}^{-1} \cdot \mathrm{day}^{-1}$ with a subsequent taper over 2-3 weeks [84].

\section{Ongoing or recurrent acute rejection}

Switch from cyclosporin A to tacrolimus. Tac has been successfully used in the treatment of intractable acute, and also chronic, rejection after kidney [85], liver [86] and heart transplantation [87].

Several small studies have assessed the effect of conversion from CsA to Tac on ongoing/recurrent acute rejection after LTx. GRIFFITH et al. [88] reported on 13 patients; recurrent acute rejection resolved in eight patients and improved in two patients. HoRNING et al. [89] studied 14 patients. The switch from CsA to Tac resulted in a marked decrease in the number of episodes of rejection per patient and in the average histological grade of rejection. ONSAGER et al. [90] showed reversal of biopsy-proven acute rejection in eight patients and stabilisation of FEV1 in three additional patients after conversion, whereas four patients did not respond to Tac rescue therapy. VITUlo et al. [91] investigated 20 lung transplant patients; conversion resulted in a reduced incidence and severity of further acute rejection episodes, in steroid sparing and in stabilisation or improvement of lung function.

An international retrospective study (not published) including data from 110 patients with ongoing/recurrent acute rejection indicated that conversion from CsA to Tac resulted in a remarkable reduction of the number of rejection episodes, whether acute rejection was diagnosed by histology or clinically, and in the number of steroid-pulse therapies. Indeed, $94 \%$ of patients experienced a decrease in the number of rejection episodes, and only $22 \%$ of patients presented documented acute rejection after the conversion from CsA to Tac.

No data are presently available regarding the incidence of BOS after the switch from CsA to Tac for recurrent acute rejection. The switch from CsA-based immunosuppression to Tac-based therapy has become the first step in the treatment of refractory acute rejection [92].

Polyclonal or monoclonal antilymphocyte antibodies. Before the advent of Tac, refractory acute rejection was usually treated with ATG or OKT3 with good clinical outcomes in some cases [93]. However, as a consequence of the multiple studies demonstrating the efficacy of Tac for the treatment of refractory acute rejection and the experience in cardiac transplant recipients, which indicated that Tac is a more efficacious and safer agent than OKT3 [94], these agents have now become second choice for the treatment of refractory acute rejection.

Other treatments. Other treatment modalities for refractory acute rejection include methotrexate (MTX) therapy [95], aerosolised CsA [96], inhaled steroids [97], total lymphoid irradiation (TLI) [98] or photopheresis [99]. However, data concerning these treatment modalities stem mainly from small single-centre studies; the effects of these therapies have not been investigated in large-scale investigations or multicentre trials. A treatment modality, which deserves a special mention, is the infusion of high-dose $\left(2 \mathrm{~g} \cdot \mathrm{kg}^{-1}\right)$ intravenous immunoglobulins (IVIg). The efficacy of IVIg for reversing acute humoral rejection in renal and cardiac allograft recipients has been established [100]. IVIg have not been studied formally for the treatment of refractory acute rejection after LTx, but favourable outcomes have been seen occasionally and, compared with other treatment options, this therapy is largely nontoxic.

Summary. First-line treatment of an episode of acute rejection are high-dose intravenous steroid pulses. First-line treatment for ongoing or recurrent acute rejection is a switch from CsA to Tac. Second choice for refractory acute rejection is treatment with ATG or OKT3. In case of failure, high-dose IVIg are worth a trial.

\section{Treatment of chronic rejection}

Treatment of established chronic rejection is difficult and deceptive. Current strategies include: 1) changing medications within therapeutic classes; 2) adding inhaled immunosuppressants; 3) augmenting the net immune suppression; and/or 4) applying other immune-modulating therapies. Although each of these approaches has some support, the majority of reports are limited by the small numbers of patients treated, retrospective study design, short duration of follow-up after treatment and/or the absence of a control group.

\section{Modification of maintenance immune suppression}

Switch from cyclosporin A to tacrolimus. Several small studies have assessed the impact of conversion from Tac to CsA in patients with established BOS [101-104]. In each study, conversion from CsA to Tac significantly decreased the monthly rate of decline in FEV1 in each BOS group with stabilisation of FEV1 values. A recent retrospective study, pooling data from 13 lung transplant programmes, indicated that there was a statistically significant decrease in the rate of loss of FEV1 after conversion to Tac. Although encouraging, these results are limited by the fact that the rate of loss of lung function in many obstructive lung diseases is nonlinear, with the rate of decline of FEV1 decreasing as airflow obstruction becomes more severe. Therefore, the possibility exists that the same results may have been observed without changing medications. Interestingly, data obtained in patients who had a $<19 \%$ decrease in FEV1 relative to baseline (pre-BOS group) showed a trend towards an increase in FEV1 values after the switch. This observation suggests that BOS may be partly reversible in some patients when the therapeutic intervention is made early in the course of the disease [105]. The updated classification of BOS, which now includes an early stage defined by a $10-19 \%$ decline in FEV1 and/or a $>25 \%$ decline in the mid-expiratory flow rate, may help identify these patients.

Substituting mycophenolate mofetil for azathioprine. Some centres have substituted MMF for Aza in patients presenting BOS and have reported stabilisation of lung function in these patients [106, 107]. However, these reports concerned a total of 14 patients with no recent follow-up data. Thus, at the present time, there is no strong evidence for this approach.

\section{Addition of inhaled immunsuppressants}

Aerosolised cyclosporin A. It is possible that currently available maintenance immunosuppressive medications would prevent chronic rejection in more recipients if they could be given in higher doses. This has led to the concept of delivering these medications directly to the lower respiratory 
tract by aerosol inhalation, thereby increasing drug delivery while decreasing systemic drug exposure. In this regard, IACONO et al. [108] have reported stabilisation of pulmonary function in seven of nine patients with chronic rejection after treatment with inhaled CsA. However, aerosolised CsA has been consistently unavailable for other investigators and there are no further data at the present time.

Inhaled steroids. In view of the prominent component of airway inflammation in BOS, it is possible that inhaled steroids would be of benefit. No data are available at the present time and large, placebo-controlled studies will be necessary to establish the impact of this approach.

\section{Augmentation of the net immunosuppression}

High-dose methylprednisolone and antilymphocyte antibodies. High-dose methylprednisolone is frequently given when the diagnosis of BOS is first evident. Unfortunately, this approach is entirely empirical and its benefits or absence of benefits have not been studied at all. ATG or OKT3 have also been frequently used to stabilise lung function in patients developing BOS before the introduction of novel immunosuppressants, such as Tac to the market. Three retrospective studies indicate that ATG may decrease or arrest the decline of lung function in patients presenting BOS for periods ranging from 3-12 months [109-111]. Significant improvement or longterm stabilisation of lung function have, however, not been reported and prospective, randomised trials evaluating ATG as a treatment for BOS are lacking. Thus, these agents should probably not be considered as a first choice for the treatment of BOS. Moreover, they may potentially induce infectious complications, which may be responsible for further deterioration of lung function.

Methotrexate and cyclophosphamide. MTX has been used to treat patients presenting BOS. The evidence is limited to one retrospective study concerning 10 patients presenting progressive BOS, who received conventional treatment plus MTX. Eight patients were evaluated: two patients improved, five patients stabilised with a follow-up of 6 months and one patient declined despite therapy [112].

Cyclophosphamide (Cyc) has also been used in seven patients to halt chronic rejection. In six of seven patients, FEV1 stabilised or increased [113].

No firm conclusion can be drawn from these small retrospective studies on MTX and Cyc. These drugs present a potentially high rate of toxicity in the already highly immunosuppressed lung transplant patient presenting BOS.

\section{Other immunomodulatory treatments}

Total lymphoid irradiation. TLI via mantle, para-aortic and inverted Y-field irradiation, delivered in fractions with a total dose of $8 \mathrm{~Gy}$, has been used to induce donor-specific tolerance before transplantation and to treat refractory acute heart, heart-lung or lung rejection [98]. In heart transplant patients, it has even been shown that conversion to Tac or TLI are equipotent strategies for refractory acute rejection [114] and that MTX or TLI are equally effective [115].

DiAMOND et al. [116] have assessed the value of TLI in 11 patients presenting BOS. A subset of four patients experienced stabilisation of pulmonary function with a mean follow-up of 11 months. It has to be stressed that a positive response to TLI occurred mainly in patients who had a long time interval between transplant and onset of BOS, a preserved FEV1 at initiation of TLI and no pre-existing pulmonary infection. HABIB et al. [117] retrospectively compared conversion to Tac and TLI in the management of BOS stage 2 or 3 in 26 lung transplant recipients. In this series, efficacy of both procedures was equal, but conversion to Tac carried less risk of infection and less mortality. This group thus suggested that conversion to Tac should be used before TLI, at least in patients with correct renal function [117].

Photopheresis. Photopheresis includes a combination of leukopheresis and administration of the photosensitive drug 8-methoxypsoralen followed by extracorporeal photoirradiation with long-wavelength ultraviolet A. This therapy was developed initially to treat patients with erythrodermic cutaneous T-cell lymphoma; its underlying mechanism of action is believed to be modulation of T-cell-mediated immunity.

SLOVIS et al. [118] reported on three patients, presenting progressive BOS after single LTx despite steroid pulses and/or ATG treatment, who stabilised after initiation of photopheresis. SALERnO et al. [119] studied eight patients with progressive BOS; photopheresis allowed stabilisation of five. VilLANUEVA et al. [120] retrospectively reviewed their experience with 14 patients diagnosed with BOS who underwent this procedure. Five of eight patients presenting early BOS (stage 0-p or 1) were stabilised [120].

It has to be stressed that photopheresis does not seem to induce any noteworthy toxic side-effect.

\section{Summary}

Treatment of chronic rejection remains one of the most difficult tasks for the physician caring for lung transplant recipients.

Patients on a CsA-based immunosuppressive regimen diagnosed with BOS should probably be switched to Tac, at least for a period of 3-6 months. On the contrary, there are no data supporting a switch from Aza to MMF in this context. High-dose steroid pulses and ATG are still frequently used to stabilise patients unresponsive to the switch from CsA to Tac, which is effective in some. The available data do not support the addition of MTX or Cyc to the maintenance immunosuppressive regime. TLI and photopheresis, especially when initiated early, seem to stabilise some patients with early BOS. These procedures are, however, not so easy to organise in practice and are most often used as a third step when a switch to Tac and/or high-dose steroids/ATG therapy has failed.

Prospective, randomised, controlled trials to analyse the impact of these different therapies on BOS are cruelly lacking at the present time.

\section{Prospects for the near future}

\section{Sirolimus and everolimus}

Sirolimus (rapamycin) is a hydrophobic, macrocyclic lactone produced by the actinomycete Streptomyces hygroscopicus, with a structure remarkably similar to Tac. Everolimus (rapamycin derivative) is a macrolide synthesised to have an enhanced bioavailability compared with that reported for sirolimus. Unlike the calcineurin inhibitors, which inhibit transcriptional activation of early T-cell specific genes and, thus, inhibit the production of T-cell growth factors, sirolimus and everolimus exert their immunosuppressive effects by blocking growth factor-driven cell proliferation of both 
haematopoietic and nonhaematopoietic cells, such as vascular and bronchial smooth muscle cells [44].

Preliminary data in animals specifically support the evaluation of these agents in lung transplant recipients, since everolimus prevents acute allograft rejection in rat models [121] and prevents epithelial destruction and luminal obliteration in a porcine heterotopic bronchial allograft model [122].

The safety and tolerability of everolimus in lung transplant recipients has been evaluated in a phase-I, multicentre, randomised, double-blind, two-period, two-sequence, crossover study. Twenty stable, lung transplant patients (12 non$\mathrm{CF}$, eight $\mathrm{CF}$ ) received single doses of everolimus $(0.035$ or $0.1 \mathrm{mg} \cdot \mathrm{kg}^{-1} \cdot \mathrm{day}^{-1}$ ) in combination with CsA, Aza and steroids. Everolimus was well tolerated at both dosages. Headache was the most common side-effect and there was a mild dose-dependent decrease in leukocyte and platelet counts. CF patients had significantly lower peak concentrations than non-CF patient, however, the overall exposure was similar in both patient groups. Concomitant administration of single doses of everolimus did not influence the steady-state pharmacokinetics of CsA, a notable finding given the fact that the two agents are intended to be administered simultaneously as part of the immunosuppressive regimen [123]. This is in contrast with sirolimus, which must be administered $4 \mathrm{~h}$ apart from CsA, due to significant pharmacokinetic interaction [124]. Phase-III studies are now ongoing to assess the longterm safety and efficacy of everolimus in lung and heart-lung transplant patients, including those with BOS.

\section{FTY720}

FTY720 is a synthetic analogue of a fungal metabolite, myriocin, which shows potent immunosuppressive activity in vitro and in vivo. FTY720's mechanism of action is not fully characterised. It induces a significant reduction in the number of circulating lymphocytes, probably by altering lymphocyte trafficking and/or homing patterns through modulation of cell-surface adhesion receptors and ligands [125]. In vivo, FTY720 displays marked synergistic effects with CsA and/or rapamycin and, thus, may improve the therapeutic windows of drugs targeting cytokine synthesis or signal transduction.

In a murine airway model, combination treatment with FTY720 and cytotoxic T-lymphocyte antigen 4-immunoglobulin $\mathrm{G}$ preserves the respiratory epithelium and prevents obliterative airway disease [126]. As such, this compound is potentially interesting for human lung transplantation.

\section{Conclusion and further prospects}

LTx has come a long way since the discovery of CsA in the early 1980s. New immunosuppressant drugs have since been discovered and with each new discovery hopes have been fuelled that it may result in a marked benefit of survival for lung transplant patients. These new drugs have been added to or have replaced agents of the original immunosuppressive regimen combining CsA, Aza and steroids. However, their use has not been able to markedly improve survival; their use has only lessened toxic side-effects and allowed the adaptation of the immunosuppressive regimen to the patient's comorbidities.

For the last 5 yrs, a huge international effort has been made to give rise to large-scale, multicentre, randomised, controlled trials. The first of these trials, the MMF trial, has now been completed with 315 patients included, and complete data will become available soon. A second trial comparing Csa versus Tac in combination with MMF and steroids is well under way. It is of the utmost importance that such trials continue to be organised and that researchers do not go back to small single-centre studies, which most often do not provide a robust answer to the initial question.

Finally, it is believed today that substantial improvement in long-term survival after lung transplantation will probably not come from any of these newly discovered immunosuppressants or their various combinations. Indeed, the authors believe that this goal will only be achieved when: 1) protocols for tolerance induction will become available for clinical solid organ transplantation; and/or 2) immunosuppression will to some extent be adapted according to the recipient's risk factors for rejection; and/or 3) when the understanding of the pathogenesis of bronchiolitis obliterans syndrome will have progressed far enough to design specifically targeted immunological and/or pharmacological interventions to halt this process.

\section{References}

1. Hertz MI, Taylor DO, Trulock EP, et al. The Registry of the International Society for Heart and Lung transplantation: nineteenth official report - 2002. J Heart Lung Transplant 2002; 21: 950-970.

2. International Society for Heart and Lung Transplantation. ISHLT Data 2002. www.ishlt.org. Accessed October 2002.

3. Glanville AR, Corris PA, McNeil KD, Wahlers T. Mycophenolate mofetil vs. azathioprine in lung transplantation for the prevention of bronchiolitis obliterans syndrome: results of a 3-year international randomised trial. J Heart Lung Transplant 2003; 22: Suppl. 1, S207.

4. Halloran P, Mathew T, Tomlanovich S, Groth C, Hooftman L, Barker C. Mycophenolate mofetil in renal allograft recipients: a pooled efficacy analysis of three randomized, double-blind, clinical studies in prevention of rejection. The International Mycophenolate Mofetil Renal Transplant Study Groups. Transplantation 1997; 63: 39-47.

5. Otulana BA, Higenbottam T, Scott J, Clelland C, Igboaka G, Wallwork J. Lung function associated with histologically diagnosed lung rejection and pulmonary infection in heart-lung transplant patients. Am Rev Respir Dis 1990; 142: 329-332.

6. van Muylem A, Antoine M, Yernault JC, Paiva M, Estenne M. Inert gas single-breath washout after heart-lung transplantation. Am J Respir Crit Care Med 1995; 152: 947-952.

7. van Muylem A, Melot C, Antoine M, Knoop C, Estenne M. Role of pulmonary function in the detection of allograft dysfunction after heart-lung transplantation. Thorax 1997; 52: 643-647.

8. Becker FS, Martinez FJ, Brunsting LA, Deeb GM, Flint A, Lynch JP 3rd. Limitations of spirometry in detecting rejection after single-lung transplantation. Am J Respir Crit Care Med 1994; 150: 159-166.

9. Otulana BA, Higenbottam T, Ferrari L, et al. The use of home spirometry in detecting acute lung rejection and infection following heart-lung transplantation. Chest 1990; 97: 353-357.

10. Morlion B, Knoop C, Paiva M, Estenne M. Internet-based home monitoring of pulmonary function after lung transplantation. Am J Respir Crit Care Med 2002; 165: 694-697.

11. Silkoff PE, Caramori M, Tremblay L, et al. Exhaled nitric oxide in human lung transplantation. A noninvasive marker of acute rejection. Am J Respir Crit Care Med 1998; 157: 1822-1828.

12. Fisher AJ, Gabbay E, Small T, Doig S, Dark JH, Corris PA. Cross sectional study of exhaled nitric oxide levels following lung transplantation. Thorax 1998; 53: 454 458.

13. Studer SM, Orens JB, Rosas I, et al. Patterns and significance of exhaled-breath biomarkers in lung transplant recipients with acute allograft rejection. $J$ Heart Lung Transplant 2001; 20: 1158-1166. 
14. Rizzo M, SivaSai KS, Smith MA, et al. Increased expression of inflammatory cytokines and adhesion molecules by alveolar macrophages of human lung allograft recipients with acute rejection: decline with resolution of rejection. $J$ Heart Lung Transplant 2000; 19: 858-865.

15. Kukafka DS, O'Brien GM, Furukawa S, Criner GJ. Surveillance bronchoscopy in lung transplant recipients. Chest 1997; 111: 377-381.

16. Boehler A, Vogt P, Zollinger A, Weder W, Speich R. Prospective study of the value of transbronchial lung biopsy after lung transplantation. Eur Respir J 1996; 9: 658-662.

17. Trulock EP, Ettinger NA, Brunt EM, Pasque MK, Kaiser LR, Cooper JD. The role of transbronchial lung biopsy in the treatment of lung transplant recipients: an analysis of 200 consecutive procedures. Chest 1992; 102: 1049-1054.

18. Swanson SJ, Mentzer SJ, Reilly JJ, et al. Surveillance transbronchial lung biopsies: implication for survival after lung transplantation. J Thorac Cardiovasc Surg 2000; 119: 27-37.

19. Valentine VG, Taylor DE, Dhillon GS, et al. Success of lung transplantation without surveillance bronchoscopy. $J$ Heart Lung Transplant 2002; 21: 319-326.

20. Sharples LD, McNeil K, Stewart S, Wallwork J. Risk factors for bronchiolitis obliterans: a systematic review of recent publications. J Heart Lung Transplant 2002; 21: 271-281.

21. Jackson CH, Sharples LD, McNeil K, Stewart S, Wallwork J. Acute and chronic onset of bronchiolitis obliterans syndrome (BOS): are they different entities? J Heart Lung Transplant 2002; 21: 658-666.

22. Estenne M, Hertz M. Bronchiolitis obliterans after human lung transplantation. Am J Respir Crit Care Med 2002; 166: $440-444$.

23. Wain JC, Wright CD, Ryan DP, Zorb SL, Mathisen DJ, Ginns LC. Induction immunosuppression for lung transplantation with OKT3. Ann Thorac Surg 1999; 67: 187-193.

24. Abramowicz D, Wissing KM, Broeders N. Induction therapy with anti-CD3 antibodies. Curr Opin Organ Transplant 1999; 4: 312-317.

25. Szczech LA, Berlin JA, Aradhye S, Grossman RA, Feldman HI. Effect of anti-lymphocyte induction therapy on renal allograft survival: a meta-analysis. J Am Soc Nephrol 1997; 8: 1771-1777.

26. Opelz G. Efficacy of rejection prophylaxis with OKT3 in renal transplantation. Collaborative Transplant Study. Transplantation 1995; 60: 1220-1224.

27. Meyers BF, Lynch J, Trulock EP, Guthrie TJ, Cooper JD, Patterson GA. Lung transplantation: a decade of experience. Ann Surg 1999; 230: 362-371.

28. Bourdage JS, Hamlin DM. Comparative polyclonal antithymocyte globulin and antilymphocyte/anti-lymphoblast globulin anti-CD antigen analysis by flow cytometry. Transplantation 1995; 59: 1194-1200.

29. Palmer SM, Miralles AP, Lawrence CM, Gaynor JW, Davis RD, Tapson VF. Rabbit antithymocyte globulin decreases acute rejection after lung transplantation: results of a randomized, prospective study. Chest 1999; 116: 127-133.

30. Griffith BP, Hardesty RL, Armitage JM, et al. Acute rejection of lung allografts with various immunosuppressive protocols. Ann Thorac Surg 1992; 54: 846-851.

31. Abouna GM, al-Abdullah IH, Kelly Sullivan D, et al. Randomized clinical trial of antithymocyte globulin induction in renal transplantation comparing a fixed daily dose with dose adjustment according to $\mathrm{T}$ cell monitoring. Transplantation 1995; 59: 1564-1568.

32. Djamali A, Turc-Baron C, Portales P, et al. Low dose antithymocyte globulins in renal transplantation: daily versus intermittent administration based on T-cell monitoring. Transplantation 2000; 69: 799-805.

33. Krasinskas AM, Kreisel D, Acker MA, et al. CD3 monitoring of antithymocyte globulin therapy in thoracic organ transplantation. Transplantation 2002; 73: 1339-1341.

34. Abramowicz D, Schandene L, Goldman M, et al. Release of tumor necrosis factor, interleukin-2, and gamma-interferon in serum after injection of OKT3 monoclonal antibody in kidney transplant recipients. Transplantation 1989; 47: 606-608.

35. Chatenoud L, Ferran C, Reuter A, et al. Systemic reaction to the anti-T-cell monoclonal antibody OKT3 in relation to serum levels of tumor necrosis factor and interferon-gamma. N Engl J Med 1989; 320: 1420-1421.

36. Kahan BD, Rajagopalan PR, Hall M. Reduction of the occurrence of acute cellular rejection among renal allograft recipients treated with basiliximab, a chimeric anti-interleukin2-receptor monoclonal antibody. United States Simulect Renal Study Group. Transplantation 1999; 67: 276-284.

37. Nashan B, Light S, Hardie IR, Lin A, Johnson JR. Reduction of acute renal allograft rejection by daclizumab. Daclizumab Double Therapy Study Group. Transplantation 1999; 67: 110-115.

38. Vincenti F, Kirkman R, Light S, et al. Interleukin-2-receptor blockade with daclizumab to prevent acute rejection in renal transplantation. Daclizumab Triple Therapy Study Group. $N$ Engl J Med 1998; 338: 161-165.

39. Beniaminovitz A, Itescu S, Lietz K, et al. Prevention of rejection in cardiac transplantation by blockade of the interleukin-2 receptor with a monoclonal antibody. $N$ Engl $J$ Med 2000; 342: 613-619.

40. Brock MV, Borja MC, Ferber L, et al. Induction therapy in lung transplantation: a prospective, controlled clinical trial comparing OKT3, anti-thymocyte globulin, and daclizumab. J Heart Lung Transplant 2001; 20: 1282-1290.

41. Garrity ER, Villanueva J, Bhorade SM, Husain AN, Vigneswaran WT. Low rate of acute lung allograft rejection after the use of daclizumab, an interleukin 2 receptor antibody. Transplantation 2001; 71: 773-777.

42. Keenan RJ, Konishi H, Kawai A, et al. Clinical trial of tacrolimus versus cyclosporine in lung transplantation. Ann Thorac Surg 1995; 60: 580-585.

43. Keenan RJ, Dauber JH, Iacono AT, Zaldonis D, Griffith BP. Long-term follow-up clinical trial of tacrolimus versus cyclosporine for lung transplantation. J Heart Lung Transplant 1998; 17: 61.

44. Palmer SM, Baz MA, Sanders L, et al. Results of a randomized, prospective, multicenter trial of mycophenolate mofetil versus azathioprine in the prevention of acute lung allograft rejection. Transplantation 2001; 71: 1772-1776.

45. Borel JF, Freurer C, Magnée C. Biological effects of cyclosporin A: a new antilymphocyte agent. Agents Actions 1976; 6: 468-475.

46. Calne RY, White DJ, Thiru S, et al. Cyclosporin A initially as the only immunosuppressant in 34 recipients of cadaveric organs: 32 kidneys, 2 pancreases, and 2 livers. Lancet 1979; ii: $1033-1036$.

47. Briffa N, Morris RE. New immunosuppressive regimens in lung transplantation. Eur Respir J 1997; 10: 2630-2637.

48. Kahan BD, Dunn J, Fitts C, et al. Reduced inter- and intrasubject variability in cyclosporine pharmacokinetics in renal transplant recipients treated with a micro-emulsion formulation in conjunction with fasting, low-fat meals, or high-fat meals. Transplantation 1995; 59: 505-511.

49. Levy G, Thervet E, Lake J, Uchida K, on behalf of the CONCERT Group. Patient management by Neoral C2 monitoring: an International Consensus Statement. Transplantation 2002; 73: S12-S18.

50. Lindholm A, Kahan BD. Influence of cyclosporine pharmacokinetics, trough concentration and AUC monitoring on outcomes after kidney transplantation. Clin Pharmacol Ther 1993; 54: 205-218.

51. Malahati K, Belitsky P, Sketris I, West K, Panek R. Neoral monitoring by simplified sparse sampling area under the concentration-time curve: its relationship to acute rejection and cyclosporine nephrotoxicity early after kidney transplantation. Transplantation 1999; 68: 55-62.

52. Mahalati K, Belitsky P, West K, et al. Approaching the therapeutic window for cyclosporine in kidney transplantation: a prospective study. J Am Soc Nephrol 2001; 12: 823-833. 
53. Kahan BD, Welsh M, Schoenberg L, et al. Variable oral absorption of cyclosporine. A biopharmaceutical risk factor for chronic allograft rejection. Transplantation 1996; 62: 599-606.

54. Halloran PF, Helms LM, Kung L, Noujaim J. The temporal profile of calcineurin inhibition by cyclosporine in vivo. Transplantation 1999; 68: 1356-1361.

55. Marsh CL. Abbreviated pharmacokinetic profiles in areaunder-the-curve monitoring of cyclosporine therapy in de novo renal transplant patients treated with Sandimmune or Neoral. Ther Drug Monit 1999; 21: 27-34.

56. Nashan B, Cole E, Levy G, Thervet E. Clinical validation studies of Neoral C2 monitoring: a review. Transplantation 2002; 73: S3.

57. Trull A, Steel L, Sharples L, et al. Randomized, trough blood cyclosporine concentration-controlled trial to compare the pharmacodynamics of Sandimmune and Neoral in de novo lung transplant recipients. Ther Drug Monit 1999; 21: 17-26.

58. Dumont RJ, Partovi N, Levy RD, Fradet G, Ensom MH. A limited sampling strategy for cyclosporine area under the curve monitoring in lung transplant recipients. J Heart Lung Transplant 2001; 20: 897-900.

59. Kesten S, Scavuzzo M, Chaparro C, Szalai JP. Pharmacokinetic profile and variability of cyclosporine versus Neoral in patients with cystic fibrosis after lung transplantation. Pharmacotherapy 1998; 18: 847-850.

60. Reynaud-Gaubert M, Viard L, Girault P, et al. Improved absorption and bioavailability of cyclosporine A from a microemulsion formulation in lung transplant recipients affected with cystic fibrosis. Transplant Proc 1997; 29: 2450-2453.

61. Glanville AR, Hopkins PM, Aboyoun PN, Chhajed PN, Plit ML, Malouf MA. Clinical utility of cyclosporin C2 monitoring after lung transplantation. $J$ Heart Lung Transplant 2002; 21: Suppl. 1, 143.

62. Knoop C, Vervier I, Thiry P, et al. Cyclosporine pharmacokinetics and dose monitoring after lung transplantation: comparison between cystic fibrosis and other conditions. Transplantation 2003; 76: 683-688.

63. Hosenpud JD, Bennett LE, Keck BM, Fiol B, Boucek MM, Novick RJ. The Registry of the International Society for Heart and Lung transplantation: sixteenth official report 1999. J Heart Lung Transplant 1999; 18: 611-626.

64. Kahan BD, Keown P, Levy GA, Johnston A. Therapeutic drug monitoring of immunosuppressant drugs in clinical practice. Clin Ther 2002; 24: 330-350.

65. Morton JM, Kear LM, Williamson S, Potter JM. Trough levels are inadequate for monitoring tacrolimus pharmacokinetics in lung transplantation. J Heart Lung Transplant 2002; 21: Suppl. 1, 144.

66. Knoop C, Thiry P, Estenne M. Tacrolimus (FK506) pharmacokinetics after lung transplantation in cystic fibrosis (CF) and non-CF patients. Abstract presented at the 5th International Congress on Lung Transplantation, Paris, September 2002.

67. Vincenti F, Jensik SC, Filo RS, Miler J, Pirsch J. A longterm comparison of tacrolimus (FK506) and cyclosporine in kidney transplantation: evidence for improved allograft survival at 5 years. Transplantation 2002; 73: 775-782.

68. Boots JMM, van Duijnhoven EM, Christiaans MHL, Nieman FH, van Suylen RJ, van Hooff JP. Single-center experience with tacrolimus versus cyclosporine-Neoral in renal transplant recipients. Transpl Int 2001; 14: 370-383.

69. Margreiter R. Efficacy and safety of tacrolimus compared with ciclosporin microemulsion in renal transplantation: a randomised multicentre study. Lancet 2002; 359: 741-746.

70. Knoll GA. Tacrolimus versus cyclosporin for immunosuppression in renal transplantation: meta-analysis of randomised trials. BMJ 1999; 318: 1104-1107.

71. Taylor DO, Barr ML, Radovancevic B, et al. A randomized, multicenter comparison of tacrolimus and cyclosporine immunosuppressive regimens in cardiac transplantation: decreased hyperlipidemia and hypertension with tacrolimus. J Heart Lung Transplant 1999; 18: 336-345.

72. Reichart B, Meiser B, Vigano M, et al. European Multicenter Tacrolimus 5FK506 Heart Pilot Study: one-year results. European Tacrolimus Multicenter Heart Study Group. J Heart Lung Transplant 1998; 17: 775-781.

73. Meiser BM, Uberfuhr $\mathrm{P}$, Fuchs A, et al. Single-center randomized trial comparing tacrolimus (FK506) and cyclosporine in the prevention of acute myocardial rejection. J Heart Lung Transplant 1998; 17: 782-788.

74. Rinaldi M, Pellegrini C, Martinelli L, et al. FK506 effectiveness in reducing acute rejection after heart transplantation: a prospective randomized study. J Heart Lung Transplant 1997; 16: 1001-1010.

75. Treede H, Klepetko W, Reichenspurner H, et al. Tacrolimus versus cyclosporine after lung transplantation: a prospective, open, randomized two-center trial comparing two different immunosuppressive protocols. J Heart Lung Transplant 2001; 20: 511-517.

76. Reichenspurner $\mathrm{H}$, Kur F, Treede $\mathrm{H}$, et al. Optimization of the immunosuppressive protocol after lung transplantation. Transplantation 1999; 68: 67-71.

77. van Gelder T, Klupp J, Barten MJ, Christians U, Morris RE. Co-administration of tacrolimus and mycophenolate mofetil does not increase mycophenolic acid (MPA) exposure, but co-administration of cyclosporine inhibits the enterohepatic recirculation of MPA, thereby decreasing its exposure. J Heart Lung Transplant 2001; 20: 160-161.

78. van Gelder T, Hilbrands LB, Vanrenterghem Y, et al. A randomized double-blind, multicenter plasma concentration controlled study of the safety and efficacy of oral mycophenolate mofetil for the prevention of acute rejection after kidney transplantation. Transplantation 1999; 68: 261-266.

79. Kobashigawa J, Miller L, Renlund $\mathrm{D}$, et al. A randomized active-controlled trial of mycophenolate mofetil in heart transplant recipients. Mycophenolate Mofetil Investigators. Transplantation 1998; 66: 507-515.

80. O'Hair DP, Cantu E, McGregor C, et al. Preliminary experience with mycophenolate mofetil used after lung transplantation. J Heart Lung Transplant 1998; 17: 864-868.

81. Ross DJ, Waters PF, Levine M, Kramer M, Ruzevich S, Kass RM. Mycophenolate mofetil versus azathioprine immunosuppressive regimens after lung transplantation: preliminary experience. J Heart Lung Transplant 1998; 17: 768-774.

82. Zuckermann A, Klepetko W, Birsan T, et al. Comparison between mycophenolate mofetil- and azathioprine-based immunosuppressions in clinical lung transplantation J Heart Lung Transplant 1999; 18: 432-440.

83. Miller J, DeHoyos A, and University of Toronto Lung Transplant Group and Washington University Lung Transplant Group. An evaluation of the role of omentopexy and of early perioperative corticosteroid administration in clinical lung transplantation. J Thorac Cardiovasc Surg 1993; 105: 247-252.

84. Haverich A, Goerler A. Modern immunosuppression strategies in lung transplantation. Curr Opin Organ Transplant 1999; 4: 249-253.

85. Woodle ES, Thistlewaite JR, Gordon JH, et al. A multicenter trial of FK506 (tacrolimus) therapy in refractory acute renal allograft rejection: a report of the tacrolimus kidney transplantation rescue study group. Transplantation 1996; 62: 594-599.

86. McDiarmid SV, Klintmalm GB, Busuttil RW. FK506 conversion for intractable rejection of liver allograft. Transplant Int 1993; 6: 305-312.

87. Armitage JM, Kormos RL, Fung J, Starzl TE. Clinical trial of FK506 as primary and rescue immunosuppression in adult cardiac lung transplantation. Transplant Proc 1991; 23: 3054-3057.

88. Griffith BP, Bando K, Hardesty RL, et al. A prospective, randomized trial of FK506 versus cyclosporine after 
human pulmonary transplantation. Transplantation 1994; 57 : 848-851.

89. Horning NR, Lynch JP, Sundaresan SR, Patterson GA, Trulock EP. Tacrolimus therapy for persistent or recurrent acute rejection after lung transplantation. J Heart Lung Transplant 1998; 17: 761-767.

90. Onsager DR, Canver CC, Jahania MS, et al. Efficacy of tacrolimus in the treatment of refractory rejection in heart and lung transplant recipients. $J$ Heart Lung Transplant 1999; 18: 448-455.

91. Vitulo P, Oggionni T, Cascina A, et al. Efficacy of tacrolimus rescue therapy in refractory acute rejection after lung transplantation. J Heart Lung Transplant 2002; 21: 435-439.

92. Garrity ER Jr, Hertz MI, Trulock EP, Keenan R, Love R. Suggested guidelines for the use of tacrolimus in lungtransplant recipients. J Heart Lung Transplant 1999; 18: 175176.

93. Shennib H, Mercado M, Nguyen D, et al. Successful treatment of steroid-resistant double-lung allograft rejection with orthoclone OKT3. Am Rev Respir Dis 1991; 144: 224-226.

94. Meiser BM, Uberfuhr P, Fuchs A, et al. Tacrolimus: a superior agent to OKT3 for treating cases of persistent rejection after intrathoracic transplantation. J Heart Lung Transplant 1997; 16: 795-800.

95. Cahill BC, O'Rourke MK, Strasburg KA, et al. Methotrexate for lung transplant recipients with steroid-resistant acute rejection. J Heart Lung Transplant 1996; 15: 1130-1137.

96. Keenan RJ, Iacono A, Dauber JH, et al. Treatment of refractory acute allograft rejection with aerosolized cyclosporine in lung transplant recipients. $J$ Thorac Cardiovasc Surg 1997; 113: 335-341.

97. De Soyza A, Fisher AJ, Small T, Corris PA. Inhaled corticosteroids and the treatment of lymphocytic bronchiolitis following lung transplantation. Am J Respir Crit Care Med 2001; 164: 1209-1212.

98. Valentine VG, Robbins RC, Wehner JH, Patel HR, Berry GJ, Theodore J. Total lymphoid irradiation for refractory acute rejection in heart-lung and lung allografts. Chest 1996; 109: 1184-1189.

99. Andreu G, Achkar A, Couetil JP, et al. Extracorporeal photochemotherapy treatment for acute lung rejection episodes. J Heart Lung Transplant 1995; 14: 793-796.

100. Jordan SC, Quartel AW, Czer LSC, et al. Posttransplant therapy using high-dose human immunoglobulin (intravenous gammaglobulin) to control acute humoral rejection in renal and cardiac allograft recipients and potential mechanism of action. Transplantation 1998; 66: 800-805.

101. Kesten S, Chaparro C, Scavuzzo M, Gutierrez C. Tacrolimus as rescue therapy for bronchiolitis obliterans syndrome. J Heart Lung Transplant 1997; 16: 905-912.

102. Ross DJ, Lewis MI, Kramer M, Vo A, Kass RM. FK506 rescue immunosuppression for obliterative bronchiolitis after lung transplantation. Chest 1997; 112: 1175-1179.

103. Mentzer RM, Jahania M.S, Lasley RD, and the US Multicenter FK506 Study Group. Tacrolimus as a rescue immunosuppressant after heart and lung transplantation. Transplantation 1998; 65: 109-113.

104. Revell MP, Lewis ME, Llewellyn-Jones CG, Wilson IC, Bonser RS. Conservation of small-airway function by tacrolimus/cyclosporine conversion in the management of bronchiolitis obliterans following lung transplantation. J Heart Lung Transplant 2000; 19: 1219-1223.

105. Bando K, Paradis IL, Similo S, et al. Obliterative bronchiolitis after lung and heart-lung transplantation. J Thorac Cardiovasc Surg 1995; 110: 4-14.

106. Speich R, Boehler A, Thurnheer R, Weder W. Salvage therapy with mycophenolate mofetil for lung transplant bronchiolitis obliterans: importance of dosage. Transplantation 1997; 64: 533-535.

107. Whyte RI, Rossi SJ, Mulligan MS, et al. Mycophenolate mofetil for obliterative bronchiolitis syndrome after lung transplantation. Ann Thorac Surg 1997; 64: 945-948.
108. Iacono AT, Keenan RJ, Duncan SR, et al. Aerosolized cyclosporine in lung recipients with refractory chronic rejection. Am J Respir Crit Care Med 1996; 153: 1451-1455.

109. Snell GI, Esmore DS, Williams TJ. Cytolytic therapy for the bronchiolitis obliterans syndrome complicating lung transplantation. Chest 1996; 109: 874-878.

110. Kesten S, Rajagopalan N, Maurer J. Cytolytic therapy for the treatment of bronchiolitis obliterans syndrome following lung transplantation. Transplantation 1996; 61: 427-430.

111. Date H, Lynch JP, Sundaresan S, Patterson GA, Trulock EP. The impact of cytolytic therapy on bronchiolitis obliterans syndrome. J Heart Lung Transplant 1998; 17: 869-875.

112. Dusmet M, Maurer J, Winton T, Kesten S. Methotrexate can halt the progression of bronchiolitis obliterans syndrome in lung transplant recipients. J Heart Lung Transplant 1996; 15: $948-954$.

113. Verleden GM, Buyse B, Delcroix M, et al. Cyclophosphamide rescue therapy for chronic rejection after lung transplantation. J Heart Lung Transplant 1999; 18: 1139-1142.

114. Keogh AM, Arnold RH, Macdonald PS, Hawkins RC, Morgan GW, Spratt PM. A randomized trial of tacrolimus (FK506) versus total lymphoid irradiation for the control of repetitive rejection after cardiac transplantation. $J$ Heart Lung Transplant 2001; 20: 1331-1334.

115. Ross HJ, Gullestad L, Pak J, Slauson S, Valentine HA, Hunt SA. Methotrexate or total lymphoid radiation for treatment of persistent or recurrent allograft cellular rejection: a comparative study. J Heart Lung Transplant 1997; 16: 179-189.

116. Diamond DA, Michalski JM, Lynch JP, Trulock EP 3rd. Efficacy of total lymphoid irradiation for chronic allograft rejection following bilateral lung transplantation. Int $J$ Radiat Oncol Biol Phys 1998; 41: 795-800.

117. Habib S, Hoskin P, Rose M, Khagani A, Yacoub M, Banner N. A comparison of tacrolimus and total lymphoid irradiation in the management of post transplant bronchiolitis obliterans syndrome. J Heart Lung Transplant 1997; 16: 136.

118. Slovis BS, Loyd JE, King LE. Photopheresis for chronic rejection of lung allografts. $N$ Engl J Med 1995; 332: 962.

119. Salerno CT, Park SJ, Kulick DM, et al. Adjuvant treatment of refractory lung transplant rejection with extracorporeal photopheresis. J Thorac Cardiovasc Surg 1999; 117: 1063-1069.

120. Villanueva J, Bhorade SM, Robinson JA, Husain AN, Garrity ER Jr. Extracorporeal photophoresis for the treatment of lung allograft rejection. Ann Transplant 2001; 5: $44-47$.

121. Hausen B, Boeke K, Berry GJ, Segarra I, Christians U, Morris RE. Suppression of acute rejection in allogeneic rat lung transplantation: a study of the efficacy and pharmacokinetics of rapamycin derivative (SDZ RAD) used alone and in combination with a microemulsion formulation of cyclosporine. J Heart Lung Transplant 1999; 18: $150-159$.

122. Salminen US, Maasilta PK, Taskinen EI, Alho HS, Ikonen TS, Harjula AL. Prevention of small airway obliteration in a swine heterotopic lung allograft model. J Heart Lung Transplant 2000; 19: 193-206.

123. Doyle RL, Hertz MI, Dunitz JM, et al. RAD in stable lung and heart/lung transplant recipients: safety, tolerability, pharmacokinetics, and impact of cystic fibrosis. J Heart Lung Transplant 2001; 20: 330-339.

124. Anonymous. Rapamune $\mathbb{R}$ (sirolimus) oral solution prescribing information. Philadelphia, Wyeth Laboratories, 1999.

125. Napoli KL. The FTY720 story. Ther Drug Monit 2000; 22: $47-51$.

126. Konishi K, Inobe M, Yamada A, Murakami M, Todo S, Uede T. Combination treatment with FTY720 and CTLAIgG preserves the respiratory epithelium and prevents obliterative disease in a murine airway model. $J$ Heart Lung Transplant 2002; 21: 692-700. 